\title{
Analisis Tingkat Kesiapan Pengguna Sistem Informasi Koreksi Essay Otomatis Berbasis Web Menggunakan Model Technology Readiness Index (TRI)
}

\author{
Rifki Adhitama ${ }^{\mathrm{a}}$, Aditya Wijayanto ${ }^{\mathrm{a}}$, Dwi Mustika Kusumawardani ${ }^{\mathrm{b}}$ \\ ${ }^{a}$ Rekayasa Perangkat Lunak, Institut Teknologi Telkom Purwokerto \\ ${ }^{a}$ Sistem Informasi, Institut Teknologi Telkom Purwokerto \\ Naskah Diterima : 12 Juni 2021; Diterima Publikasi : 23 Januari 2022
}

DOI: 10.21456/vol11iss2pp161-167

\begin{abstract}
During the pandemic, the learning model directly impacts both students and teachers, especially in evaluating and correcting assignments to measure student learning. Evaluation and correction of the learning process at both the high school and high school and university levels are generally carried out multiple-choice examinations during this pandemic. Many tools can be used to carry out multiple-choice assessments. The essay assessment is usually done manually and takes a long time because the lecturer has to make corrections one by one. On the other hand, information retrieval is a concept that can be used to build an automatic essay correction information system so that the correction of essay questions can be done quickly and efficiently, as in multiple-choice works. The automatic essay correction information system is a relatively new technology, especially for its plural use in this pandemic. A new technology that will be applied in a plural manner requires a measurement. One of the measurements that can be used is the Technology Readiness Index (TRI). TRI is used because it can measure the readiness and tendency of users to implement an information system. The case study in this research was conducted at the Faculty of Informatics (FIF) Telkom Institute of Technology Purwokerto (ITTP). The TRI measurement of the automatic essay correction information system carried out at FIF produces a TRI of 3.27. This value is between 2.90 and $3.51(2.90 \leq \mathrm{TRI} \leq 3.51)$. Consisted of an optimism value of 1.01 , and innovativeness value of 0.52 , a discomfort value of 0.55 , and an insecurity value of 1.19 .
\end{abstract}

Keywords: Technology Readiness Index; Pandemic Examination; Information Retrieval; Information System.

\begin{abstract}
Abstrak
Model pembelajaran di masa pandemi berimbas secara langsung baik ke siswa maupun pengajar, khususnya dalam melakukan evaluasi dan koreksi tugas untuk mengukur pembelajaran mahasiswa. Evaluasi dan koreksi pada proses pembelajaran baik pada level sekolah menengah maupun sekolah tinggi dan universitas umumnya dilakukan dengan ujian pilihan ganda di masa pandemi ini, dikarenakan telah banyak tools yang dapat digunakan untuk melakukan penilaian pilihan ganda. Adapaun penilaian essay biasanya masih dilakukan secara manual, dan memakan waktu yang cukup lama karena harus melakukan koreksi satu persatu. Di lain sisi information retrieval merupakan salah satu konsep yang dapat digunakan untuk membangun sebuah system informasi koreksi essay otomatis sehingga koreksi soal essay dapat dilakukan secara cepat dan efisien seperti pada koreksi pilihan ganda. Sistem informasi koreksi soal essay otomatis merupakan sebuah teknologi yang relative baru, khususnya untuk digunakan secara jamak di masa pandemic ini. Sebuah teknologi baru yang akan diterapkan secara jamak memerlukan sebuah pengukuran, salah satu pengukuran yang dapat digunakan adalah Technology Readiness Index (TRI). Penelitian ini bertujuan untuk menerapkan TRI untuk mengukur kesiapan dan kecenderungan pengguna terhadapa implementasi suatu system informasi. Studi kasus dalam penelitian ini dilakukan di Fakultas Informatika (FIF) Institut Teknologi Telkom Purwokerto (ITTP). Hasil pengukuran TRI terhadap system informasi koreksi essay otomatis yang dilakukan di FIF menghasilkan hasil TRI sebesar 3,27. Nilai tersebut berada diantara 2,90 sampai 3,51 (2,90 TRI $\leq 3,51$ ). Nilai 3,27 yang didapatkan terdiri dari nilai optimism sebesar 1,01 , nilai innovativeness sebesar 0,52 , nilai discomfort sebesar 0,55 , dan nilai insecurity sebesar 1,19 .
\end{abstract}

Keywords: Technology Readiness Index; Pandemic Examination; Information Retrieval; Information System.

\section{Pendahuluan}

Evaluasi proses pembelajaran merupakan salah satu parameter untuk menilai sejauh mana proses transfer ilmu dan informasi yang telah diterima oleh audiens yang merupakan siswa ataupun mahasiswa. Dalam pembelajaran salah satu instrument yang dapat digunakan untuk melakukan evaluasi adalah

*) Penulis korespondensi: dwi.mustika@ittelkom-pwt.ac.id 
ujian, beberapa bentuk ujian yang sering dilakukan adalah ujian tertulis yang didalamnya termasuk essay dan pilihan ganda dan ujian lisan.

Evaluasi atau peningkatan kompetensi pada proses pembelajaran baik pada level sekolah menengah maupun sekolah tinggi dan universitas umumnya dilakukan dengan ujian essay atau pilihan ganda. Penilaian evaluasi pada pilihan ganda jauh lebih mudah daripada penilaian evaluasi dari soal essay. Terlebih lagi sudah terdapat beberapa tool yang mampu digunakan untuk melakukan penilaian pada evaluasi pilihan ganda antara lain Kahoot (2020) dan SurveyMonkey (2020), atau bahkan dengan google form. Sedangkan untuk soal essay masih belum secepat dan semudah penilaian pada soal essay. Permasalahan yang sering dihadapi oleh para guru, dosen maupun instruktur adalah menilai hasil evaluasi yang berbentuk essay karena memakan waktu yang cukup lama. Hal ini disebabkan menilai hasil evaluasi essay harus membaca antara kunci ataupun instrument kunci jawaban dengan jawaban masing-masing siswa/mahasiswa. Konsistensi penilaian juga terkadang menjadi bias ketika pengajar sudah kelelahan ataupun dalam kondisi yang sudah tidak kondusif untuk menilai jawaban essay dari siswa. Padahal untuk menilai jawaban essay dibutuhkan konsentrasi dan focus lebih daripada menilai jawaban pilihan ganda.

Untuk mempermudah penilaian soal essay, dan pergeseran pembelajaran yang mayoritas saat ini dilakukan secara online dapat dibangun suatu sistem informasi yang mampu melakukan penilaian soal essay secara otomatis. Sistem tersebut dapat melakukan identifikasi kemiripan antara kunci jawaban dan jawaban siswa. Pembuatan system ini dapat menggunakan information retrieval ataupun text mining. Text mining dan information retrieval merupakan beberapa teknik yang dapat digunakan untuk menyelesaikan permasalahan yang telah dijabarkan sebelumnya. Beberapa penelitian tentang text mining telah dilakukan. Salah satunya adalah penelitian tentang ekstraksi topik di dalam suatu dokumen berita menggunakan Latent Dirichlet Allocation (LDA) (Adhitama, Kusumaningrum and Gernowo, 2017), pengkalsifikasian opini masyarakat (Jumeilah, 2018), pengkalsifikasian tugas akhir berdasarkan abstraknya (Hermanto, 2016) dan penggunaan metode Machine Readable Dictionary (MRD) untuk menilai kedekatan kalimat pada sebuah jawaban (Hayatin, 2015).

Penelitian ini menggunakan pendekatan metode Vector Space model (VSM) untuk membuat sistem informasi yang mampu melakukan penilaian otomartis terhadap beberapa jawaban sekaligus. Metode VSM digunakan karena VSM memiliki kelebihan dalam pencocokan query. Dimana VSM mampu mencocokkan sebagian query dengan dokumen yang ada. Disamping itu metode juga mudah beradaptasi melalui penyesuaian parameter termasuk parameter pembobotannya. Sehingga dapat menghasilkan dampak yang besar terhadap kualitas hasil (Kowalski dan Maybury, 2002).

Di lain sisi penerapan teknologi yang relative baru memerlukan sebuah pengukuran kesiapan teknologi, salah satu metode yang dapat digunakan untuk melakukan analisis kesiapan teknologi adalah model Technology readiness Index (TRI). TRI dalah ukuran kecenderungan sesorang untuk mau menggunakan sebuah teknologi baru ang bertujuan untuk memudahkan kehidupan sehari harinya(Yusuf, Syamfithriani and Mirantika, 2020). Pengukuran TRI menggunakan 4 Variabel yaitu optimism, (optimisme), innovativeness (inovasi), discomford (ketidaknyamanan), insecurity (ketidakamanan) (Parasuraman, 2000).

Berdasarkan urian yang telah disampaikan, maka penelitian ini bertujuan untuk membangun sebuah sistem infomrasi penilaian essay otomatis yang dapat menilai dan mencocokkan kunci dengan jawaban secara bersamaan dan melakukan pengukuran kesiapan teknologinya berdasarkan model TRI. Penelitian ini diharapkan dapat ikut berkontribusi dalam memajukan dunia pendidikan di Indonesia khususnya di masa pandemic ini, karena nantinya aplikasi ini dapat digunakan secara offline ataupun online, sehingga dapat lebih friendly untuk digunakan pada sekolah sekolah yang memiliki infrastruktur rata-rata atau dapat pula digunakan oleh pengajar umtuk memberikan lebih banyak latihan untuk meningkatkan kompetensi siswa.

\section{Kerangka Teori}

\subsection{Information Retrieval}

Pencarian informasi atau dokumen yang berdasarkan pada suatu query yang betujuan untuk memenuhi harapan user dari sekumpulan dokumen yang ada disebut sebagai Information retrieval. Query di dalam Information Retrieval merupakan sebuah model atau formula yang biasa digunakan oleh pengguna untuk mencari suatu informasi yang dibutuhkan. sebuah query merupakan suatu keywords (kata kunci) dan dokumen yang mengandung keywords merupakan dokumen yang dicari dalam information retrieval.

Tahpan-tahapan dalam menemukan informasi dalam information retrieval dibagi ke dalam dua tahapan utama yaitu Indexing subsystem dan Searching subsystem. Tahapan Indexing subsystem yaitu tahapan pembentukan susunan dokumen yang sesuai dengan struktur yang telah ditentukan agar dapat dilakukan pengolahan untuk tahpan yang selanjutnya yaitu tahapan searching subsystem. Searching subsistem merupakan tahapan menemukan dokumen atau informasi yag diharapkan yang sesuai dengan hasil tahapan pertama (Baeza-Yates dan Ribeiro-Neto, 2010). 
Pada tahapan pertama untuk mempercepat proses pencarian pada dokumen, khususnya dokumen teks, diperlukan adanya sebuah dokumen indexing. Proses indexing dokumen dibagi ke dalam bebrapa tahapan yaitu mulai dari tokenisasi, stopword removal, stemming, dan pembobotan. Proses indexing pada dokumen teks diilustrasikan pada Gambar 1 .

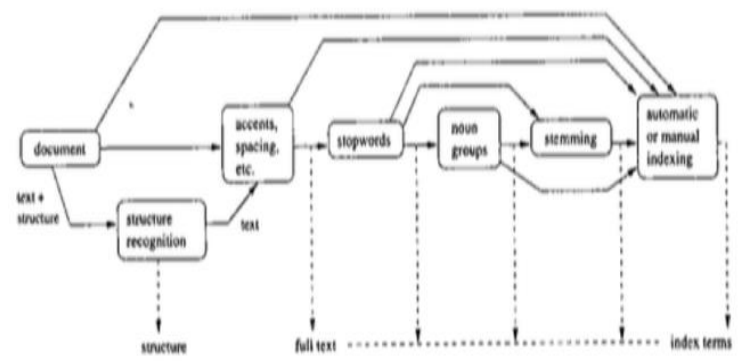

Gambar 1. Proses Indexing Dokumen Teks

a. Tokenisasi - Tokenisasi merupakan proses pemotongan atau pemisalah suatu kalimat di dalam dokumen menjadi token-token atau sebuah kata tunggal (tremmed word). Symbol maupun tanda baca dilangkan pada tahapan tokenisasi ini, dan merubah semua huruf menjadi huruf kecil (lowercase).

b. Stopword removal - Stopword removal merupakan proses untuk menghilangkan kata umum (commom words) yang tidak memiliki makna signifikan di dalam sebuah dokumen. Dalam Bahasa Indonesia misalnya seperti, jika, bila, atau, dll.

c. Stemming - Stemming merupakan proses untuk menghilangkan imbuhan pada setiap kata. Penghilangan imbuhan bertujuan untuk mengembalikan setiap token/kata ke dalam bentuk dasarnya. Proses stemming dalam Bahasa Indonesia yaitu menghilangkan sufiks, prefiks, dan konfiks.

d. Pembobotan - Pembobotan merupakan proses untuk memberikan kriteria kata (term) yang sering muncul di dalam sebuah dokumen secara individu, namun jarang ditemui pada dokumen lainnya.

\subsection{Technology readyness Index (TRI)}

Technology Readiness Index (TRI) adalah ukuran kecenderungan sesorang untuk mau menggunakan sebuah teknologi baru ang bertujuan untuk memudahkan kehidupan sehari harinya, pengukuran variabel TRI terdiri dari empat (4) variabel yang dapat dilihat pada Gambar 2 (Parasuraman, 2000):

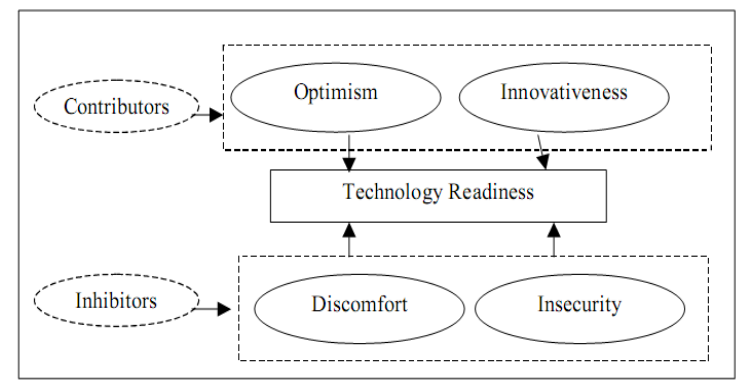

Gambar 1. Proses Indexing Dokumen Teks (Parasuraman, 2000)

Berdasarkan Gambar 2 tersebut dapat diketahui variabel dalam, TRI antara lain (Parasuraman, 2000):

a. Optimism - Keyakinan yang beranggapan bahwa teknologi dapat memberikan kesempatan yang lebih baik dalam pengendalian, fleksibilitas dan efiseiensi.

b. Inovativeness - Pengukuran tendensi sesseorang dalam menjadi pionir dalam setiap aspek.

c. Discomfort - ukuran rasa tidak nyaman dalam penggunaan teknologi.

d. Insecurity - Rasa ketidakamanan dalam penggunaan teknologi dan kecenderungan lebih menggunakan etode konvensional.

Kemudian TRI memiliki Tiga kategori penerapan yaitu:

a. Low - Kesipan pengguna yang rendah ditandai dengan nilai TRI $<2.89$.

b. Medium - Kesiapan pengguna dianggap cukup dan siap dengan nilai TRI 2.90 sampai 3.51.

c. High - Kesiapan dan ketertarikan pengguna tinggi ditandai dengan nilai TRI > 3.51.

Perhitungan nilai TRI dihitung berdasarkan perkalian antara nilai mean dari masing-masing kuesioner dengan bobot tiap pernyataan. Masing masing variabel memiliki bobot terhadap total sebesar $25 \%$. Kemudian membagi bobot terhadap total dengan jumlah pernyataan dari masing-masing variabel. Jika bobot masing-masing pernyataan $n$ telah didapatkan, maka langkah selanjutnya adalah mengkalikan nilai mean dari pernyataan tersebut dengan bobot masing-masing pernyataan. Perhitungan tersebut dilakukan untuk memperoleh skor total tiap pernyataan. Skor variabel diperoleh dari jumlah total skor pernyataan pada variabel tersebut. Sedangkan untuk mendapatkan skor total TRI dihitung berdasarkan jumlah nilai seluruh variabel. Proses perhitungan nilai TRI masingmasing variabel ditunjukkan dengan rumus pada persamaan 2.1, persamaan 2.2, persamaan 2.3, dan persamaan 2.4 . 


$$
\begin{aligned}
& \text { Bobot Pernyataan }=\frac{25 \%}{\sum \text { pernyataan variabel }} \\
& \text { Nilai Pernyataan }=\frac{\sum(\text { jumlah jawaban } x \text { skor } \text { jawaban })}{\text { iumlah responden }} \times \text { Bobot pernyataan } \\
& \text { Nilai variabel }=\sum \text { nilai pernyataan } \\
& \text { Nilai } T R I=\sum \text { skor variabel }
\end{aligned}
$$

\subsection{Questioner}

Kuesioner atau yang biasa disebut dengan angket merupakan daftar pertanyaan sebagai salah satu bahan penelitian. Kuesioner dapat dilakukan dengan dua cara yakni kuesioner secara terbuka dan tertutup. Kuesioner terbuka memberikan kesempatan responden dalam menjawab sesuai dengan kalimatnya sendiri. Sedangkan kuesioner tertutup dapat dilakukan responden dengan memilih jawaban yang telah disediakan (Ahmad et al., 2021).

\section{Metode}

Metode penelitian menjelaskan tahapan - tahapan penelitian yang dilakukan pada penelitian ini. Tahapan dimulai dari observasi lapangan untuk merumuskan masalah. Setelah itu dilakukan sampai menghasilkan output penelitian. Bahan penelitian yang digunakan adalah data yang didapat dari hasil observasi. Selain observasi, data yang diperoleh berasal dari berbagai sumber penelitian lain (buku, laporan, jurnal, kuesioner dan sebagainya)

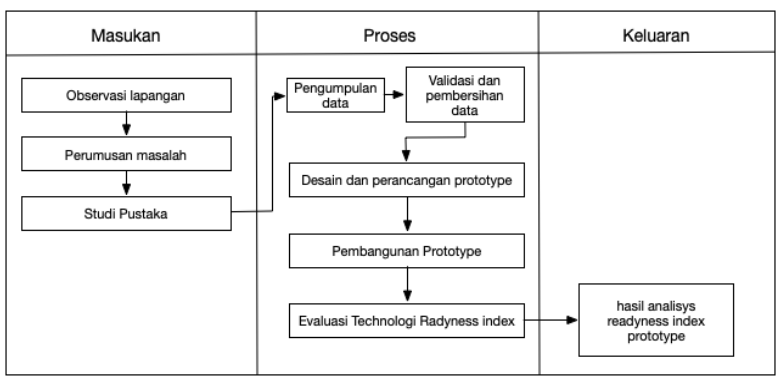

Gambar 3. Diagram Alir Penelitian

Berdasarkan diagram alir penelitian tersebut dapat dijelaskan bahwa awal penelitian dimulai dengan melakukan observasi lapangan yang menghasilkan perumusan masalah. Hasil observasi lapangan kemudian dikaji dengan mengumpulkan berbagai sumber pustaka. Setelah sumber pustaka ditentukan, maka mulai dilakukanlah pengumpulan data dengan menyebarkan kuesioner.

Kuesioner diberikan kepada responden yang dalam penelitian ini merupakan dosen FIF ITTP sebagai pengguna Koreksiin. Teknik pengambilan sampel responden dilakukan dengan menggunakan Teknik quota sampling, dimana jumlah sampel ditentukan berdasarka ciri tertentu hingga jumlah kuota yang diperlukan dalam penelitan telah tercukupi (Septiani et al., 2020). Kuesioner pada penelitian ini diberikan kepada responden dalam bentuk form yang berisi pernyataan berdasarkan keempat faktor pada metode TRI untuk mengukur kesiapan pengguna terhadap sistem informasi koreksi essay otomatis berbasis Web. Responden mengisikan form kuesioner berdasarkan prototyping yang diberikan. Responden dalam penelitian ini adalah Dosen dari beberapa Program Studi suatu intitusi pedidikan. Sampel penelitian dengan teknik quota sampling yaitu salah satu teknik pengambilan sampel menetapkan jumlah responden yang akan diteliti terlebih dahulu, kemudian memilih anggota sampel yang diperlukan dalam penelitian (Sanusi, 2011).

Pernyataan yang terdapat pada kuesioner dibuat berdasarkan kategori dalam metode TRI. Pernyataan kuesioner yang digunakan dalam penelitian ini bersifat positif dan negatif. Pernyataan yang bersifat positif yaitu optimism dan innovativeness, sedangkan pernyataan yang bersifat negatif yaitu discomfort dan insecurity (Yusuf et al., 2020). Susunan pilihan jawaban yang diberikan dibuat berdasarkan Skala Linkert 1-5. Pernyataan pada form kuesioner yang

\begin{tabular}{|c|c|}
\hline Variabel & Pernyataan \\
\hline \multirow{7}{*}{$\begin{array}{l}\text { Optimisme } \\
\text { (Optimism) }\end{array}$} & $\begin{array}{lll}\begin{array}{l}\text { Layanan } \\
\text { digunakan }\end{array} & \text { koreksi.in } & \text { nyaman } \\
\end{array}$ \\
\hline & $\begin{array}{l}\text { Saya lebih suka melakukan penilaian } \\
\text { hasil pekerjaan mahasiswa } \\
\text { menggunakan Koreksi.in karena tidak } \\
\text { memakan waktu }\end{array}$ \\
\hline & $\begin{array}{l}\text { Saya lebih suka menggunakan } \\
\text { Koreksi.in dalam melakukan penilaian } \\
\text { hasil pekerjaan mahasiswa }\end{array}$ \\
\hline & $\begin{array}{l}\text { Saya suka menggunakan tools dan } \\
\text { fitur Koreksi.in yang dapat } \\
\text { disesuaikan dengan kebutuhan saya }\end{array}$ \\
\hline & $\begin{array}{l}\text { Saya merasa Koreksi.in dapat } \\
\text { mendorong untuk mengerjakan tugas } \\
\text { saya }\end{array}$ \\
\hline & $\begin{array}{l}\text { Koreksi.in memberikan saya lebih } \\
\text { banyak kebebasan dalam beraktifitas }\end{array}$ \\
\hline & $\begin{array}{l}\text { Dengan menggunakan Koreksi.in, } \\
\text { saya tidak terlambat mengumpulkan } \\
\text { rekap nilai }\end{array}$ \\
\hline \multirow{4}{*}{$\begin{array}{c}\text { Inovasi } \\
\text { (Innovativeness) }\end{array}$} & $\begin{array}{l}\text { Banyak orang yang datang pada saya } \\
\text { untuk meminta pendapat tentang } \\
\text { Koreksi.in }\end{array}$ \\
\hline & $\begin{array}{l}\text { Saya dapat mengetahui perkembangan } \\
\text { Koreksi.in dan layanan terbarunya } \\
\text { tanpa bantuan dari orang lain }\end{array}$ \\
\hline & Saya mengikuti perkembangan \\
\hline & $\begin{array}{l}\text { Koreksi.in di bidang minat saya } \\
\text { Saya menikmati tantangan untuk } \\
\text { mencari tahu tentang fitur Koreksi.in } \\
\text { terbaru }\end{array}$ \\
\hline $\begin{array}{l}\text { Ketidaknyamanan } \\
\text { (Discomfort) }\end{array}$ & $\begin{array}{l}\text { Dukungan teknis terkadang tidak } \\
\text { banyak membantu karena mereka } \\
\text { tidak menjelaskan hal-hal yang dapat } \\
\text { saya mengerti }\end{array}$ \\
\hline
\end{tabular}
disebarkan kepada responden dapat dilihat pada Tabel 1.

Tabel 1. Daftar pernyataan kuesioner 


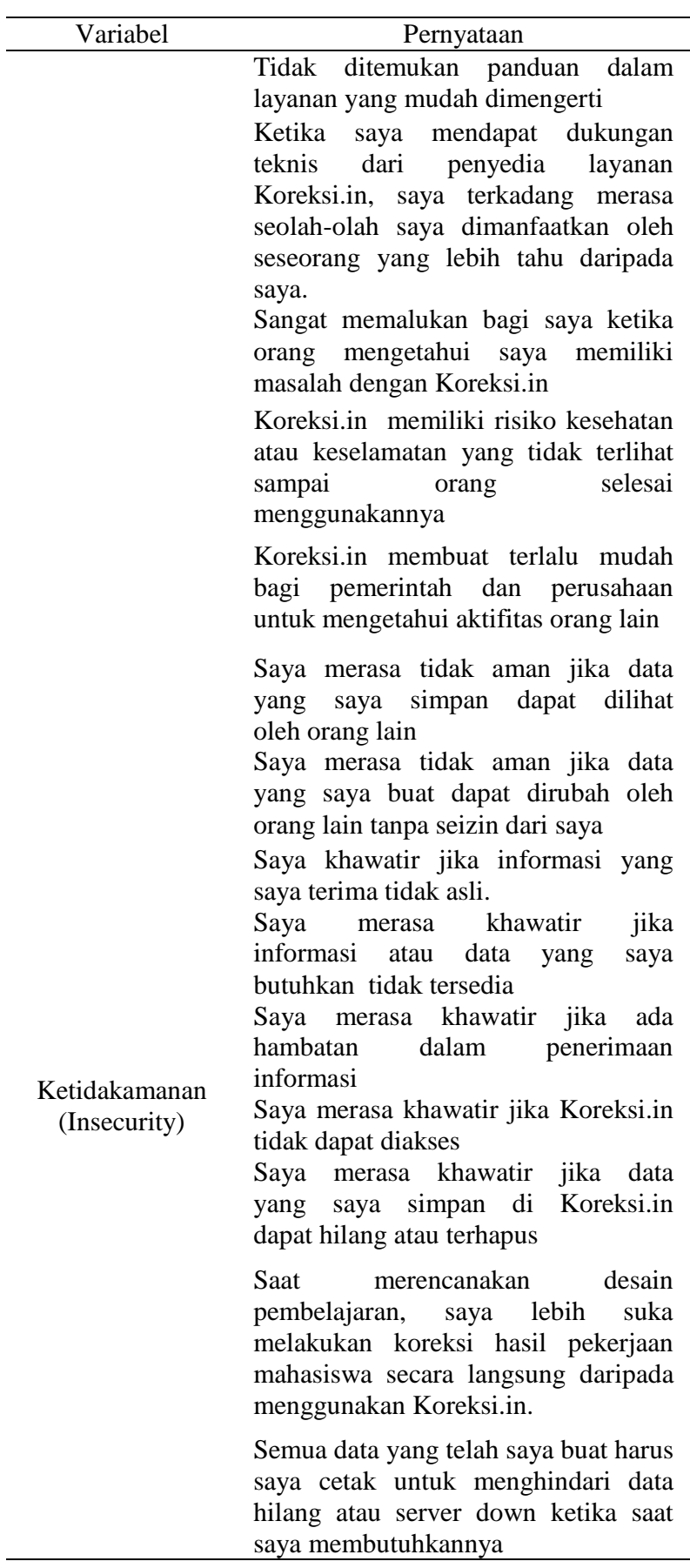

Setelah didapatkan data hasil kuesioner, selanjutnya dilakukan analisis tingkat kesiapan pengguna terhadap sistem informasi koreksi essay otomatis berbasis web dengan menggunakan metode TRI. Analisis tingkat kepuasan pengguna dengan menggunakan metode TRI dilakukan untuk menganalisis sejauh mana tingkat kesiapan seseorang dalam mengadopsi teknologi terbaru. Empat variabel pengukuran yang digunakan yaitu Optimism, Inovative, Discomfort, dan Insecurity (Cahyani, Pradnyana and Sugihartini, 2020).

Langkah - langkah metode perhitungan nilai TRI (Yusuf, Syamfithriani and Mirantika, 2020):
1. Menghitung nilai mean dari masing-masing kuisioner yang dikaitkan dengan bobot tiap pernyataan.

2. Bobot variabel terhadap total sebesar $25 \%$.

3. Membagi bobot terhadap total dengan jumlah pernyataan dari masing-masing variabel.

4. Mengkalikan nilai mean dari pernyataan tersebut dengan bobot masing-masing pernyataan. Langkah ini dilakukan untuk mendapatkan skor total tiap pernyataan.

5. Menghitung skor dengan menjumlahkan total skor pernyataan yang terdapat pada variabel tersebut.

6. Menghitung skor total TRI dengan menjumlahkan nilai seluruh variabel.

Proses bisnis dari sistem informasi koreksi essay otomatis yang akan dibangun digambarkan dalam diagram blok kerangka sistem informasi pada Gambar 4.

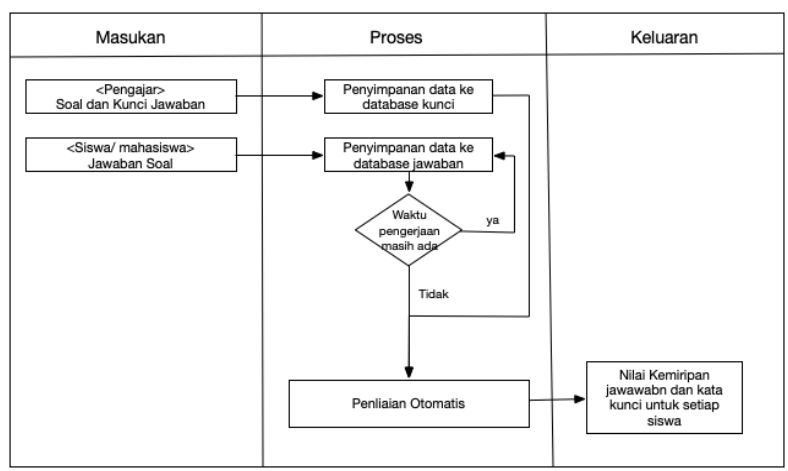

Gambar 4. Kerangka Sitem Informasi

Berdasarkan Gambar 4 di atas dapat diketahui bahwa masukan pada sistem Koreksiin terdapat dua macam, yaitu berupa soal dan kunci jawaban yang telah disusun oleh pengajar atau dosen dan jawaban soal dari mahasiswa sebagai peserta ujian atau kuis. Sistem Koreksiin akan memproses masukan berupa soal dan kunci jawaban dengan cara menyimpan kata kunci ke dalam database kunci Sedangkan masukan berupa jawaban soal akan disimpan pada database jawaban. Jika terdapat soal yang belum terjawab atau ingin diubah, maka perubahan tersebut akan diupdate pada database jawaban. Jika pengerjaan soal telah habis, maka akan langsung dilakukan penilaian secara otomatis oleh sistem Koreksiin. Proses penilaian secara otomatis oleh sistem Koreksiin diperoleh dengan cara menilai tingkat kemiripan antara jawaban dan kata kunci yang telah dimasukkan sebelumnya. Hasil dari nilai kemiripan merupakan luaran dari sistem Koreksiin.

\section{Hasil dan Pembahasan}

\subsection{Hasil}

Responden yang digunakan dalam penelitian ini merupakan Dosen suatu Perguruan Tinggi. Sampel yang diambil adalah 20 dosen dari 26 responden. 
Pemilihan sampel dilakukan dengan menggunakan quota sampling. Berdasarkan mertode tersebut, 20 responden yang digunakan sebagai data sample dianggap sudah mewakili masing - masing Program Studi di lingkungan FIF ITTP sebagai populasi pada penelitian ini. Data responden dalam penelitian ini dapat dilihat pada Gambar 4.

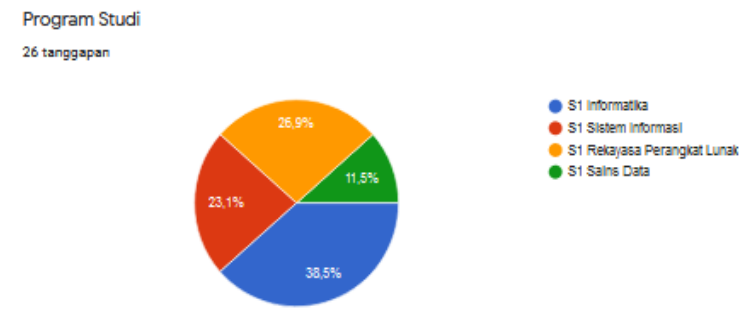

Gambar 4. Data Responden

Berdasarkan hasil kuesioner pada Gambar 4, dapat diketahui bahwa data yang didapatkan kemudian dianalisis dengan menggunakan metode TRI. Analisis ini dilakukan dengan tujuan untuk mengetahui tingkat kesiapan pengguna terhadap Sistem Informasi Koreksi Essay Otomatis Berbasis Web. Langkah pertama dalam penelitian ini adalah pengelompokan data yang disesuaikan dengan variabel dalam penelitian. Metode TRI dalam penelitian ini dimulai dengan melakukan perhitungan mean tiap item pernyataan. Nilai mean tersebut dapat diperoleh dengan menjumlahkan perkalian bobot tiap pernyataan sesuai nilai skala likert yang digunakan. Setelah itu dibagi dengan jumlah responden yang digunakan dalam penelitian ini. Bobot masing masing variabel adalah sebesar $25 \%$. Bobot tersebut kemudian dibagi dengan jumlah pernyataan yang diberikan pada tiap variabel. Skor TRI tiap variabel didapatkan dengan mengkalikan nilai mean tiap pernyataan dengan bobot terhadap total yang telah dihitung sebelumnya. Skor total TRI diperoleh dengan menjumlahkan keseluruhan skor total tiap pernyataan pada masing - masing variabel. Langkah selanjutnya yang perlu dilakukan adalah menghitung skor total TRI dengan melakukan penjumlahan keseluruhan total tiap variabel. Skor hasil dari perhitungan TRI Sistem Informasi Koreksi Essay Otomatis Berbasis Web dapat dilihat pada Tabel 1.

Tabel 1. Skor Hasil Perhitungan TRI

\begin{tabular}{ll}
\hline \multicolumn{1}{c}{ Variabel } & Skor \\
\hline Optimisme (Optimism) & 1,01 \\
Inovasi (Innovativeness) & 0,52 \\
Ketidaknyamanan (Discomfort) & 0,55 \\
Ketidakamanan (Insecurity) & 1,19 \\
\hline \multicolumn{1}{c}{ Total TRI } & 3,27 \\
\hline
\end{tabular}

Berdasarkan Tabel 1 dapat diketahui bahwa:

1. Nilai variabel Optimisme sebesar 1,01, hal tersebut menunjukkan bahwa Dosen pada Perguruan Tinggi tersebut kepercayaan bahwa sistem informasi koreksi essay otomatis berbasis web ini membawa perubahan positif bagi pekerjaan khususnya untuk kegiatan penunjang pembelajaran.

2. Nilai variabel Inovasi yang dihasilkan adalah sebesar 0,52 menunjukkan tingkat inovasi yang rendah terhadap sistem informasi koreksi essay otomatis berbasis web.

3. Berdasarkan nilai ketidaknyamanan sebesar 0,55 dapat diketahui bahwa Dosen pada Perguruan Tinggi tersebut masih kurang nyaman dengan adanya informasi koreksi essay otomatis berbasis web.

4. Nilai ketidakamanan yang dihasilkan dalam penelitian ini adalah sebesar 1,19. Nilai tersebut menunjukkan bahwa Dosen pada Perguruan Tinggi tersebut menilai tingkat keamanan informasi koreksi essay otomatis berbasis web masih rendah.

Berdasarkan nilai masing - masing variabel tersebut didapatkan skor total nilai TRI sebesar 3,27. Skor total nilai tersebut menunjukkan bahwa Dosen pada Perguruan Tinggi tersebut memiliki tingkat kesiapan yang cukup dalam menerima dan menggunakan sistem informasi koreksi essay otomatis berbasis web. Jika dilihat dari sisi kategori metode TRI, maka sistem informasi koreksi essay otomatis berbasis web masuk ke dalam kategori medium dengan nilai 3,27 yang berada di antara 2.90 sampai 3.51. Hal tersebut dapat terjadi akibat rendahnya nilai inovatif sebagai variabel pendorong dan tingginya nilai ketidak amanan.

\subsection{Pembahasan}

Penelitian yang dilakukan menghasilkan skor total nilai TRI untuk menganalisis tingkat kesiapan pengguna sistem informasi koreksi essay otomatis berbasis web. Berdasarkan hasil penelitian tersebut dapat diketahui bahwa tingkat kesiapan pengguna sistem informasi tersebut termasuk dalam kategori sedang atau medium. Hal tersebut dilihat berdasarkan nilai dari masing - masing variabel. Variabel optimisme 1,01 yang menunjukkan bahwa sistem informasi koreksi essay otomatis berbasis web akan memberikan dampak positif, yaitu dengan adanya sistem tersebut dapat meringankan pekerjaan mengkoreksi dan memberikan nilai secara otomatis sehingga dapat mempersingkat waktu dan biaya pengerjaan. Hal tersebut berbanding dengan nilai variabel inovasi sebesar 0,52. Nilai tersebut menunjukkan sistem informasi koreksi essay otomatis berbasis web yang dinilai kurang. Jika dilihat dari nilai variabel ketidaknyamanan yang memiliki nilai 0,55 , maka dapat dikatakan bahwa sistem informasi koreksi essay otomatis berbasis web dinilai cukup nyaman untuk digunakan. Fitur - fitur yang disediakan dalam sistem informasi ini sesuai kebutuhan dan mudah digunakan serta dipelajari. 
Nilai total variabel ketidaknyamanan yang didapatkan sebesar 0,55. Hal tersebut menunjukkan bahwa pengguna sistem yaitu Dosen merasa bahwa sistem yang dibangun cukup nyaman. Hal tersebut berbanding terbalik dengan variabel ketidakamanan sebesar 1,19. Berdasarkan hasil tersebut dapat diketahui bahwa Dosen atau pengguna dari sistem merasa kurang aman tentang data - data atau informasi yang terdapat dalam sistem tersebut.

Berdasarkan hasil penelitian yang dilakukan dapat diketahui bahwa tingkat kesiapan pengguna terhadap sistem informasi koreksi essay otomatis berbasis web berada dalam kategori medium atau sedang dengan nilai 3,27 berada diantara nilai 2,90 hingga 3,51 .

\section{Kesimpulan}

Berdasarkan hasil analisis data dan pembahasan yang telah dilakukan, maka kesimpulan dari penelitian ini adalah sebagai berikut:

Hasil dari pengujian menggunakan TRI, didapatkan hasil berupa tingkat kesiapan pengguna terhadap Sistem Informasi Koreksi Essay Otomatis Berbasis Web menggunakan Model Technology Readiness Index tergolong dalam kategori Medium. Hal tersebut didapatkan dengan melihan hasil dari total nilai TRI yang didapatkan yaitu 3,27. Nilai

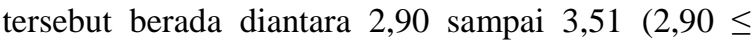
TRI $\leq 3,51)$. Nilai 3,27 yang didapatkan terdiri dari nilai optimism sebesar 1,01 , nilai innovativeness sebesar 0,52 , nilai discomfort sebesar 0,55 , dan nilai insecurity sebesar 1,19 . Berdasarkan hasil penelitian tersebut, rekomendasi atau usulan yang dapat diberikan kepada pihak institusi pendidikan lebih memperhatikan keamanan data dan informasi dalam membangun website sistem informasi Koreksi Essay Otomatis. Adapun saran untuk penelitian selanjutnya adalah penelitian tentang tingkat kesiapan dari sisi teknologi sistem informasinya. Hal tersebut perlu dilakukan agar sistem yang dibangun lebih sesuai dengan keinginan dan kebutuhan dari pengguna.

\section{Ucapan Terima Kasih}

Penulis mengucapkan terima kasih atas dana penelitian ini yang didukung oleh Kemenristekdikbud - Tahun 2020. Terima kasih juga penulis ucapkan kepada rekan - rekan dosen di lingkungan FIF ITTP yang telah bersedia mencoba sistem Koreksiin dan menjadi responden pada penelitian ini.

\section{Daftar Pustaka}

Adhitama, R., Kusumaningrum, R. Gernowo, R., 2017. Topic labeling towards news document collection based on Latent Dirichlet Allocation and ontology', in 2017 1st International
Conference on Informatics and Computational Sciences (icicos). Semarang.

Ahmad, F., Pudjiarti E dan Sari E.P., 2021. Penerapan metode technology readiness index untuk mengukur tingkat kesiapan anak sekolah dasar melakukan pembelajaran berbasis online pada SD Muhammadiyah 09 Plu', JTIM: Jurnal Teknologi Informasi dan Multimedia. pp 21-31

Baeza-Yates, R dan Ribeir N.B., 2010. Modern Information Retrieval: The Concepts and Technology Behind Search. Second Edi. ACM Press Books.

Cahyani, T.N.D., Pradnyana, I.M.A. and Sugihartini, N., 2020. Pengukuran tingkat kesiapan pengguna sistem informasi data pokok pendidikan dasar menggunakan technology readiness index ( TRI ) (studi kasus: sekolah dasar di kecamatan sukasada ). 9: 88-95.

Hayatin, N., 2015. Sistem Penilaian Jawaban Essay Otomatis Berdasarkan Nilai Kedekatan Kalimat', in Seminar Teknologi dan Rekayasa (SENTRA), pp. 169-172.

Hermanto, A., 2016. Implementasi text mining menggunakan naive bayes untuk penentuan kategori tugas akhir mahasiswa berdasarkan abstraksinya', Konvergensi, 11(01).

Jumeilah, F.S., 2018. Klasifikasi opini masyarakat terhadap jasa ekspedisi JNE dengan Naïve Bayes. Jurnal Sistem Informasi Bisnis, 8(1): 92.

Kahoot, 2020. Available at: https://kahoot.com/ (Accessed: 18 September 2020).

Kowalski, G.J and Maybury, M.T., 2002. Information storage and retrieval systems Theory and Implementation Second Edition. Second Edi. Edited by B. Croft. New York: Kluwer Academic Publishers.

Parasuraman, A., 2000. Technology Readiness Index (Tri): a multiple-item scale to measure readiness to embrace new technologies', Journal of Service Research, 2(4): 307-320.

Sanusi, A., 2011. Metodologi Penelitian Bisnis. Penerbit Salemba.

Septiani, Y., Arribe E., Diansyah, R., 2020. Analisis kualitas layanan sistem informasi akademik universitas abdurrab terhadap kepuasan pengguna menggunakan metode sevqual (Studi Kasus : Mahasiswa Universitas Abdurrab Pekanbaru). Jurnal teknologi dan open source. pp 131-143.

Surveymonkey, 2020. Available at: https://www.surveymonkey.com/ (Accessed: 18 September 2020).

Yusuf, F., Syamfithriani, T.S. dan Mirantika, N. 2020. Analisis Tingkat Kesiapan Pengguna ELearning Universitas Kuningan Dengan Menggunakan Model Techonology Readiness Index (Tri), Nuansa Informatika, 14(2):39. 